\title{
The role of attention and familiarity in face identification
}

\author{
MARGARET C. JACKSON and JANE E. RAYMOND \\ University of Wales, Bangor, Wales
}

\begin{abstract}
How is attention allocated during face identification? Previous work using famous and unfamiliar faces suggests that either no attention or a special attentional mechanism is required. We used a conventional attentional blink $(\mathrm{AB})$ procedure to measure face identification with temporarily reduced attention. The participants viewed a rapid series of face images with one embedded nonface abstract pattern (T1). They judged the texture of $\mathrm{T} 1$ and then detected a prespecified face (T2) presented at varying lags after T1. T2 was either famous or unfamiliar, as were distractor faces. Regardless of distractor type, detection of an unfamiliar T2 face was significantly impaired at short versus long T1-T2 lags, indicating an attentional requirement for face identification. Detection of a famous T2 face was unaffected by lag, suggesting that familiarity protects against a temporal attentional bottleneck. These findings do not support propositions that face identification is "special" in its need for attentional control.
\end{abstract}

Human faces are complex stimuli that vary only subtly among individuals. In spite of the perceptual challenge presented by this class of stimuli, humans are remarkably adept at recognizing a large number of different people. In this study, we investigated the possibility that this exceptional perceptual capacity might be accompanied by a special attentional control mechanism.

It has been suggested that, because of the extreme social relevance of face recognition, humans might have evolved special perceptual mechanisms dedicated to (e.g., Kanwisher, 2000; Moscovitch \& Moscovitch, 2000; Tanaka \& Sengco, 1997), or at least specially suited for (Gauthier, Skudlarski, Gore, \& Anderson, 2000; Gauthier \& Tarr, 2002; Rossion, Gauthier, Goffaux, Tarr, \& Crommelinck, 2002), face processing. The idea that the perceptual processing of faces might make use of a special set of mechanisms is rooted in three lines of evidence. The first, derived from human brain imaging studies, is that a specific brain area, the fusiform face area (FFA), is selectively activated by face stimuli and not by stimuli from other equally complex categories (Grill-Spector, Knouf, \& Kanwisher, 2004; Kanwisher, McDermott, \& Chun, 1997; McCarthy, Puce, Gore, \& Allison, 1997). Such findings are supported by event-related potential (ERP) and magnetoencephalography (MEG) studies that showed facespecific activation signatures, the N170 and the M170, respectively (Bentin, Allison, Puce, Perez, \& McCarthy, 1996; Jeffreys, 1996; Liu, Harris, \& Kanwisher, 2002; Liu, Higuchi, Marantz, \& Kanwisher, 2000). The second line of evidence comes from neuropsychological studies of patients with different discrete brain lesions that

Correspondence should be addressed to J. E. Raymond, School of Psychology, University of Wales, Bangor, Gwynedd LL57 2AS, Wales (e-mail: j.raymond@bangor.ac.uk). have revealed a double dissociation for the recognition of faces versus other objects (De Renzi, 1997; Moscovitch, Winocur, \& Behrmann, 1997). The third line of evidence comes from behavioral studies that demonstrated that face perception was dramatically impaired by inversion of the image (e.g., Farah, Tanaka, \& Drain, 1995; Tanaka \& Farah, 1993). Because inversion has considerably less impact on the perception of other classes of stimuli, this has been taken to indicate that face processing involves a unique orientation-sensitive mechanism that is not used for processing other types of stimuli. However, an inversion effect for images of human bodies (Reed, Stone, Bozova, \& Tanaka, 2003) and dogs (for dog experts; Diamond \& Carey, 1986) has also been reported, suggesting that inversion effects might be a property of a wider class of stimuli for which expertise has been developed.

Setting aside the controversial issue of whether or not face processing involves a special perceptual mechanism, the question we addressed in this study is whether face identification requires special use of attentional mechanisms. Three different views on this topic have been expressed. The first is that face processing is automatic, is obligatory, and requires no attention (e.g., Farah, 1996; Farah, Wilson, Drain, \& Tanaka, 1995). This view has plausibility because humans are unarguably expert face analyzers, and it is well established that little or no attention is needed when processing stimuli for which expertise has been developed (e.g., Schneider \& Shiffrin, 1977; Shiffrin \& Schneider, 1977). This view suggests that familiarity might play a role in attentional allocation during face processing; this was investigated in the experiments reported here. Support for this no-attention hypothesis comes from studies that reported significant interference of irrelevant face distractors on a name-categorization task (Young, Ellis, Flude, McWeeny, \& Hay, 1986), even when attention was directed away from face distractors 
by a target task with high perceptual load (Lavie, Ro, \& Russell, 2003). These studies suggested that, when no attention is applied to a face, face identity information can still be processed to a level that can cause interference with an ongoing task.

A second view regarding the role of attention in face processing, referred to here as the special-attention hypothesis, is that separate attentional resources are available for featural and configural perceptual mechanisms and that optimal face processing requires access to a facespecific attentional resource dedicated to configural processing (Palermo \& Rhodes, 2002). This view is based on the considerable behavioral and neuropsychological evidence that face perception uses both a configural and a featural processing mode (e.g., Bartlett \& Searcy, 1993; Moscovitch et al., 1997; Rhodes, Brake, \& Atkinson, 1993; Sinha \& Poggio, 1996). Configural, or holistic, processing refers to encoding information about the whole face, especially information about the relationship among face features. Featural processing refers to encoding information about parts of the face.

Palermo and Rhodes's (2002) ideas were derived from a series of dual-task experiments in which participants were required to match the identity of two peripherally presented faces (primary task) while concurrently encoding face features in a centrally presented face (secondary task). Feature recognition was subsequently tested using isolated face parts or whole faces. Their idea, based on a finding by Tanaka and Farah (1993), was that, if the central face had been encoded configurally, then feature recognition would be better with whole faces than with isolated face parts. This result was found when the peripheral faces were inverted. But, with upright peripheral faces, no difference in feature recognition between whole faces and isolated parts was observed. On the basis of the assumption that only upright faces engage configural processing, Palermo and Rhodes proposed that the observed dual-task cost reflected demands on a special, limited-capacity, configural attention mechanism. Their logic was that, if the upright peripheral face-matching task fully engaged this mechanism, there would be little configural processing capacity left for the central face-recognition task, and this would result in a loss of the whole-face advantage. Although interesting, it is not clear that these findings reflect attentional processing of face information or retrieval from working memory, because of the task used. It is possible that capacity limitations in visual working memory for faces (Jackson \& Raymond, 2004), rather than attentional limitations, provide a better account of these findings.

Support for the notion of a special configural attention mechanism was, however, provided by Awh et al. (2004). They found greater performance costs when attention was divided between two configural face tasks than when divided between a face and a nonface (featural) task. However, numerous studies have demonstrated greater dual-task costs when target stimuli for each task were perceived to be of the same stimulus class than when they were not (e.g., repetition blindness tasks; Kanwisher \& Potter, 1990). Explanations for such effects generally in- volve interference effects in working memory, rather than proposing separate attentional mechanisms.

Directly contradicting the view that optimal face processing requires access to a configural attention mechanism, but consistent with the dual-attentional resource notion, is a proposal put forward by Boutet, Gentes-Hawn, and Chaudhuri (2002). They proposed that configural aspects of face processing do not require any attention, whereas featural aspects do. They used the composite effect to explore the role of attention in configural processes. In their experiments, participants viewed faces and houses presented in transparency at the same spatial location. In one condition, participants were asked to attend to faces (and ignore houses); in another condition, participants were asked to attend to houses (and ignore faces). They then made recognition judgments of face composites (faces created by merging the top half of one face with the bottom half of another face) that were either aligned or misaligned horizontally. Boutet et al. found that, regardless of how attention was allocated during the face exposure phase, recognition was facilitated by misalignment by the same amount, even though overall recognition performance was reduced in the attend-houses condition. Benefit of misalignment (i.e., the composite effect) is thought to occur because misalignment disrupts automatic configural processing of the composite, thereby facilitating recognition of half of a previously seen face (Carey \& Diamond, 1994; Hole, 1994; Young, Hellawell, \& Hay, 1987). Finding the same size composite effect with and without full attention to faces at learning was interpreted to indicate that configural face processing does not require attention. To the extent that configural processing is seen as a special property of face processing (Farah, Wilson, et al., 1995), Boutet et al.'s view can also be seen as a version of the no-attention hypothesis.

Both the no-attention view and the special-attention view can be contrasted with a third default hypothesis. In this view, attention is needed to process faces in the same way as is needed for any other complex stimuli (Downing, Liu, \& Kanwisher, 2001; Wojciulik, Kanwisher, \& Driver, 1998). The default view is supported by observations that activation in face-specific brain areas was modulated by the degree of attentional allocation to faces (Downing et al., 2001; Pessoa, McKenna, Gutierrez, \& Ungerleider, 2002; Vuilleumier, Armony, Driver, \& Dolan, 2001; Wojciulik et al., 1998). Additionally, visual search tasks requiring detection of a face stimulus among nonface distractors was shown to be effortful (i.e., response time was set size dependent), indicating that attention is needed for face processing (Brown, Huey, \& Findlay, 1997; Kuehn \& Jolicœur, 1994; Nothdurft, 1993). Importantly, the default view has parsimony, a feature lacking in the suggestion of separate attentional mechanisms for configural versus featural processes. Indeed, the special-attention view is broadly inconsistent with numerous cross-modal attention studies that have indicated a single attentional mechanism for all sensory modalities tested (i.e., visual, auditory, tactile; e.g., Arnell \& Jolicœur, 1999; Jolicœur, 1999; SotoFaraco et al., 2002; but also see Pashler, 1998). 
To summarize, three views of the role of attention in face processing are (1) no attention is needed, (2) a special attention mechanism is needed, or (3) attention is needed as with any other stimulus. The extant empirical literature indicates that attention can enhance performance on face perception tasks, yet attention might not always be necessary for the extraction of information from a face; when attentional resource has been allocated to a face, other face stimuli appear to compete more heavily for this resource than do nonface stimuli. Put this way, the role of attention in face processing does not seem particularly special, and these summarizing statements apply well to other stimuli. For example, object perception is degraded without attention (as in inattentional blindness; Mack \& Rock, 1998); information about an object can be extracted without directing attention to it (as in negative priming; Tipper \& Cranston, 1985); and dual-task costs are greater when target stimuli for each task are of the same stimulus class than when they are not (as in repetition blindness tasks; Kanwisher \& Potter, 1990).

Note also that two factors complicate interpretation of the experimental outcomes of previous studies. One is that famous or otherwise highly familiar faces were used in some experiments, whereas others used unfamiliar or recently learned faces. Evidence exists that processing highly familiar faces (Buttle \& Raymond, 2003; Tong \& Nakayama, 1999) and nonface stimuli (Shapiro, Caldwell, \& Sorensen, 1997), relative to processing unfamiliar, recently learned stimuli, requires less attention to elevate processing above a recognition threshold. In other words, familiarity rather than stimulus class might be the determining factor in how much attention is needed for face identification. A second factor also known to modulate attention is the categorical, semantic, or featural uniqueness of a stimulus among its temporally or spatially contiguous distractors (Barnard, Scott, Taylor, May, \& Knightley, 2004; Folk, Leber, \& Egeth, 2002; Shen \& Reingold, 2001). Unique stimuli often show pop-out effects, are more difficult to ignore, and are more effective at competing for attention in divided attention tasks. In some of the studies outlined above, faces were presented as a unique item within a trial, allowing the possibility that stimulus uniqueness might have determined their attentional allocation, rather than their stimulus class per se.

Our goal was to investigate the role of attention in face identification while controlling for and manipulating the familiarity and uniqueness (within a trial) of the target stimuli. We used a divided attention task, specifically the attentional blink (AB) paradigm (Raymond, Shapiro, \& Arnell, 1992), to produce a controlled interval of reduced attentional capacity. The AB procedure uses rapid serial visual presentation (RSVP) and requires participants to divide attention between two successive targets (T1 and T2), identifying or detecting both. The interval (or lag) between the onsets of each target is varied. The AB effect is a significant impairment of T2 detection when the lag between T1 and T2 is less than about $500 \mathrm{msec}$ (Raymond et al., 1992). Because the effect is abolished if the T1 task is fully ignored, the AB appears to have an at- tentional basis. It is generally accounted for by assuming that a limited-capacity attention mechanism is needed to produce a durable, distinct representation of each target in working memory (WM; Shapiro, Arnell, \& Raymond, 1997). When engaged by the T1 task, this mechanism is temporarily unavailable or less efficient for dealing with the T2 stimulus. If T2 is presented during this interval, its representation lacks robustness and may therefore be more susceptible to interference from other stimuli already or subsequently consolidated in WM (Raymond, Shapiro, \& Arnell, 1995; Shapiro, Raymond, \& Arnell, 1994), or it may decay before its consolidation into WM is complete (Chun \& Potter, 1995). However, if a durable, robust representation of $\mathrm{T} 2$ could be produced without drawing on the slow, limited-capacity attentional mechanism needed for the T1 task, the lag between T1 and T2 would not determine $\mathrm{T} 2$ detection.

The AB paradigm is therefore useful for assessing the attentional demands of object identification, and we exploited it here to probe the role of attention in face identification. If face identification requires attention, a significant dual-task cost in detecting a specific $\mathrm{T} 2$ face presented at short, but not long, T1-T2 lags should be observed. Conversely, if face identification places few demands on attentional resources expended by the $\mathrm{T} 1$ item, this $\mathrm{AB}$ effect might be absent. Our approach involved presenting a full RSVP stream of faces with a nonface abstract image as T1 and a face as T2. (T2 was therefore never unique on a stimulus class dimension.) We specifically used a T1 task that was featural (requiring participants to make a shape judgment regarding texture elements in a pattern) to test the notion of a hypothetical attentional resource dedicated to configural processing and needed for identifying upright faces (Awh et al., 2004; Palermo \& Rhodes, 2002). This special-attention view would predict that no AB should be evident using a featural T1 stimulus. If the attentional demands of face processing are not special in this way, then AB effects should emerge.

In Experiment 1, all target and distractor faces were unfamiliar. In Experiment 2, two different groups of participants (from different countries) were asked to detect target faces of people that were highly familiar in one country and somewhat familiar in the other country, within a stream of unfamiliar distractor faces. This design allowed us to measure $A B$ effects using a single set of faces but with two different levels of familiarity, thereby isolating familiarity effects from stimulus artifacts. In Experiment 3, the distractor faces used in the RSVP display were highly familiar faces and the T2 faces were either highly familiar or unfamiliar. Comparison of these conditions with the previous experiments allowed us to determine the influence of T2 uniqueness on T2 performance (i.e., its ability to pop out of the RSVP display due to differential familiarity from distractors).

\section{GENERAL METHOD}

\section{Participants}

The participants were recruited from the University of Wales, Bangor, student and community subject panels, and they received 
course credit or money in exchange for participation. All were white European adults who reported normal or corrected-to-normal vision and were naive to the purpose of their experiment. Informed consent was obtained prior to participation. No participant completed more than one experiment.

\section{Apparatus}

The stimuli were displayed on a 22 -in. Mitsubishi DiamondPro 2060u monitor (32-bit true color; resolution 1,280 × 1,024 pixels) and were generated by E-Prime software (Version 1.0; Schneider, Eschman, \& Zuccolotto, 2002) using a Dell computer. Responses were recorded via the computer keyboard. A chinrest stabilized the participants' head position and ensured the display was always viewed binocularly from a distance of $70 \mathrm{~cm}$. Testing was conducted in a small room with low ambient illumination.

\section{Stimuli and Design}

Each trial consisted of 15 items presented successively in RSVP at the same central screen location. One of these, T1, was a computergenerated grayscale, abstract, elliptical pattern composed of either 20 small circles or 25 small squares, each element having a gray value randomly selected (with replacement) from 10 levels (see Figure 1). Ten exemplars of each pattern type (circles/squares) were used in each experimental block of trials. A T1 item was presented on every trial, and its serial position was randomly selected as 3, 4, or 5. On half of the trials, it was a circles pattern; on the remaining trials, it was a squares pattern, randomized.

All other items were faces; each was a grayscale image of a Caucasian adult, seen in frontal view, with hair present, neutral expression, and neither teeth nor glasses visible. Faces were either unfamiliar or famous (referred to here as highly familiar). We use the term unfamiliar for simplicity and to refer to a face unlikely to have been seen by the participants before the experiment began. However, these faces were all seen several times during the course of the experiment, as described below.

Unfamiliar faces were selected from the Psychological Image Collection at Stirling (PICS) database. Famous faces were selected from Google Image Web search results; famous names were used as search terms. In order to mirror the natural diversity of faces, we made no attempt to match selected faces on dimensions, such as attractiveness or distinctiveness. Luminance and contrast of face images were not manipulated, because only reasonably high quality images were used and no obvious, systematic differences on these dimensions between famous and unfamiliar faces were apparent. All images (face and nonface) were displayed against a gray rectangular uniform background that subtended approximately $2.9^{\circ} \times 3.4^{\circ}$. Each face within the background subtended an average of $2.8^{\circ} \times$ $3.3^{\circ}$. Minor variations in face/head size reflected natural individual differences (see Figure 2 for face image examples).

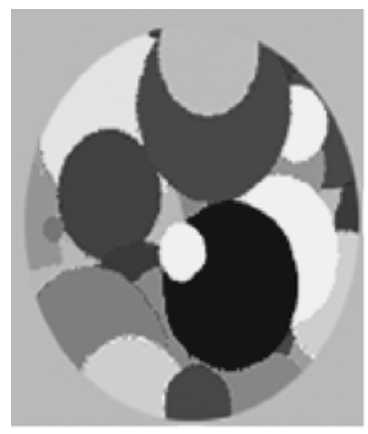

Circles

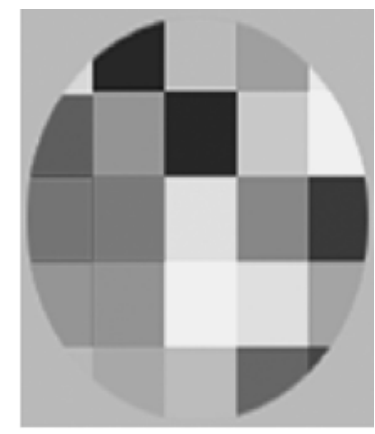

Squares
Figure 1. Examples of T1 items: circles and squares.
In each experimental block, $\mathrm{T} 2$ was the same adult male and was presented on half of all trials. When presented, it always appeared after T1 and had a lag of 1-8. A minimum of two items followed T2 to complete the RSVP series. On T2 absent trials, a T2 filler item was presented in its place. This was one of eight randomly selected different adult male faces matched in apparent age to that of the T2 face. The item following T2 (T2 mask) was randomly selected from eight other adult males, also matched in apparent age to that of the T2 face. All other faces (distractors) varied in apparent age; half were female and half were male. Each factorial combination of T1 serial position, T2 lag, and T2 presence/absence was presented on an equal number of trials, in a pseudorandom order. Each block was composed of 192 trials. Collapsing across T1 serial position, T2 was presented 12 times at each lag.

\section{Procedure}

The participants initiated each RSVP trial (illustrated in Figure 3) by pressing the space bar. A central fixation cross (font size 18) appeared for $1,000 \mathrm{msec}$ and was immediately followed by a 15 -item RSVP series. Each item, presented at the same location as the fixation cross, was presented for $85 \mathrm{msec}$ with no interstimulus interval (ISI). The participants were required to identify the abstract image (T1) as a circles or a squares pattern (using key C labeled "circles" and key N labeled "squares") and to report whether or not the prespecified target face (T2) was present (using key K labeled "yes" and key S labeled "no"). Both responses were unspeeded, and no feedback was provided.

Before beginning each experimental block, the participants completed four short practice blocks designed to deliver a consistent amount of pretest exposure to the T2 face used in the succeeding experimental block and to ensure familiarity with the two tasks. Practice blocks were like experimental blocks in all respects, with the following exceptions. First, performance feedback on both T1 and T2 tasks was provided at the end of every trial. Second, the presentation duration of each RSVP item was reduced in each successive practice block, beginning with $400 \mathrm{msec}$, reducing to $300 \mathrm{msec}$, then $200 \mathrm{msec}$, and finishing with $85 \mathrm{msec}$ (the value used in the experimental blocks). Third, each practice block had only 12 trials (50\% T2 present). Within each practice block, T2 was presented at lags 2, 5, and 7, appearing twice at each lag. This yielded a total of 24 exposures to T2 in the complete practice session. Before the practice session began, the $\mathrm{T} 2$ face was presented in the center of the screen with instructions to examine the face carefully before proceeding. As a reminder, the $\mathrm{T} 2$ face was presented once more before the experimental block. The participants tended to examine the face for approximately $5-10 \mathrm{sec}$ before initiating the first trial of a block.

\section{Data Analysis}

Data regarding performance on the $\mathrm{T} 2$ task were analyzed only if the $\mathrm{T} 1$ response had been correct on that trial. T2 false alarm (FA) rate (i.e., the percentage of "present" responses when T2 was absent) was calculated for each participant, and if this value exceeded $20 \%$ that participant's data were excluded. We also excluded data from participants whose mean T2 hit rate (percentage of "present" responses when $\mathrm{T} 2$ was present) exceeded $98 \%$. The number of participants excluded on these bases varied across experiments and is detailed in each relevant section.

For each remaining participant, we calculated a post-AB baseline level of T2 detection by averaging the hit rates obtained at lags 6 , 7 , and 8 . This measure was based on indication from prior studies that the $\mathrm{AB}$ is typically completed when the interval between $\mathrm{T} 1$ and $\mathrm{T} 2$ is greater than approximately $500 \mathrm{msec}$. A repeated measures ANOVA using T2 hit rates obtained at lags 6, 7, and 8 (conducted separately for each experiment) showed a nonsignificant effect of lag in all cases, justifying the use of this method for establishing baseline. AB magnitude was determined for each participant by calculating the difference between the hit rate at baseline and the hit 

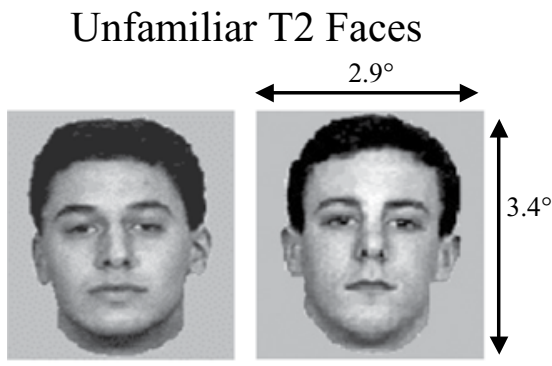

\section{Famous T2 Faces}

Unfamiliar Distractor Faces
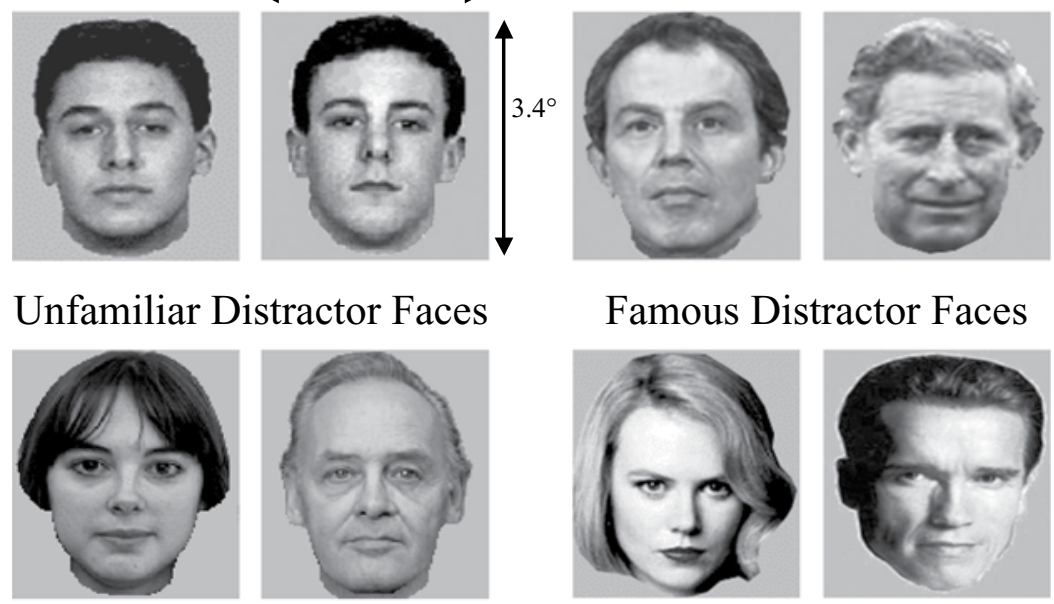

Famous Distractor Faces

Figure 2. Examples of unfamiliar T2 faces, famous T2 faces (Tony Blair, Prince Charles), unfamiliar distractor faces, and famous distractor faces (Nicole Kidman, Arnold Schwarzenegger).

rate obtained at the lag producing the minimum group mean performance (excluding lag 1).

In each experiment, repeated measures ANOVAs on T2 hit rate using lag $(1,2,3,4,5$, and baseline) as a within-participants factor were conducted to test for overall effects of lag on T2 performance.
(We also repeated all analyses using a $d^{\prime}$ score and found similar results in all cases.) Planned post hoc comparisons used pairedsamples $t$ tests (with Bonferroni corrections where applicable) to test for specific differences in $\mathrm{T} 2$ performance between short and long lags. Alpha levels were set at .05.

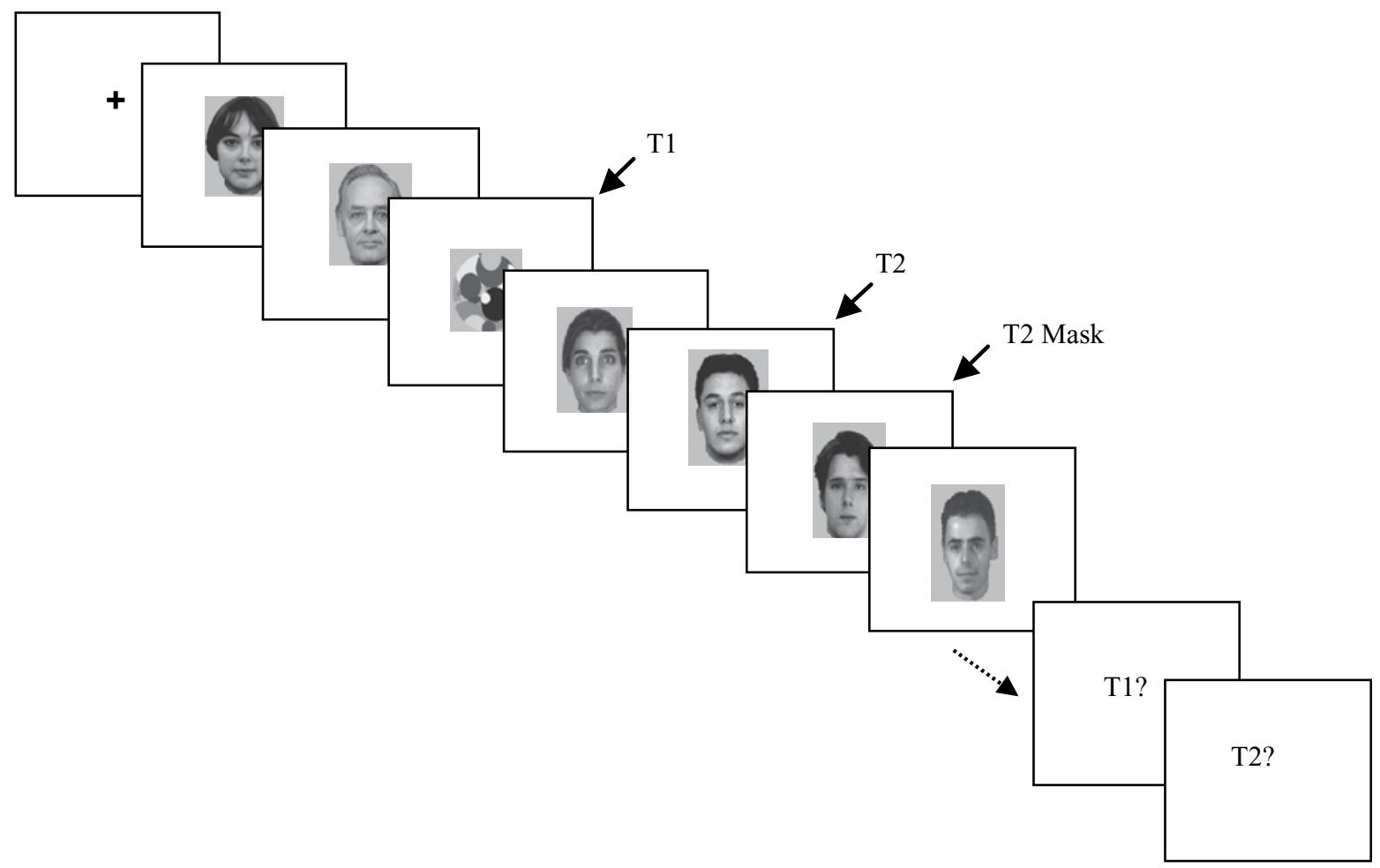

Figure 3. Example RSVP sequence illustration, with $T 1$ at Serial Position 3 and $T 2$ at lag 2 . Each item was presented for 85 msec with no interstimulus interval. 


\section{EXPERIMENT 1}

Our goal in Experiment 1 was to establish whether an $\mathrm{AB}$ effect for unfamiliar faces could be found using a featural T1 task. Awh et al. (2004) reported a series of experiments using a modified $\mathrm{AB}$ paradigm (consisting of only four items: T1 and its mask, and T2 and its mask), examining the role of attention in face processing. In their study, each task required discrimination among three exemplars of a specific stimulus class (e.g., digits or faces), with a spatial attention shift required in between. When the T1 task required digit discrimination and the $\mathrm{T} 2$ task required face discrimination, they reported no $\mathrm{AB}$ effect. In contrast, when both $\mathrm{T} 1$ and $\mathrm{T} 2$ tasks required face discrimination, an $\mathrm{AB}$ effect was found. On the basis of the assumption that digit discrimination requires the use of only featural processes and face discrimination requires both featural and configural processes, they concluded that, unless the T1 task specifically engages configural processing, face identification is unaffected by a temporal attentional bottleneck. Like Palermo and Rhodes (2002), they postulated that configural processing engages a special attentional "channel" that is distinct from the attentional channel used to process featural information. This dual-channel account predicts an $\mathrm{AB}$ effect for faces only when $\mathrm{T} 1$ processing occupies both featural and configural channels.

\section{Method}

In Experiment 1, we tested this prediction directly by presenting a 11 task that required only featural processing (i.e., discrimination of a feature element shape in a texture patch) and a T2 face identification task. We used two different unfamiliar T2 faces, testing each in a single session using two different groups. In this experiment, T2 masks, T2 fillers, and distractor faces were also unfamiliar. The method was as outlined in the General Method section.

Twenty-six British participants (14 females, 12 males; mean age 22 years) were randomly assigned to one of two face groups. Data from 4 participants were excluded due to an excessively high FA rate, leaving 13 participants in one group and 9 in the other.

\section{Results}

We first examined the effect of target face by conducting a mixed design repeated measures ANOVA on T2 hit rates with face (Face 1 and Face 2) as a between-participants factor and lag (1, 2, 3, 4, 5, and baseline) as a withinparticipants factor. This revealed a nonsignificant main effect of face and a nonsignificant face $\times$ lag interaction. On this basis, and because we were not concerned with attentional requirements for specific individual faces, data from both faces were combined for further analyses in this and all subsequent experiments in which two exemplars of T2 were used.

T1 performance. The mean percent correct score for the T1 task was $96.3 \%(S E=0.6 \%)$, and all participants performed at $85 \%$ or better. In this and all subsequent experiments reported here, an ANOVA of T1 performance using lag as a within-participants factor showed a nonsignificant main effect of lag.

T2 performance. The mean T2 FA rate was $8.8 \%$ $(S E=1.4 \%) . \mathrm{T} 2$ percent correct scores on target-present trials (hit rates) as a function of lag are shown in Figure 4. An ANOVA of these data using lag $(1,2,3,4,5$, and baseline) as a within-participants factor revealed a significant main effect of lag $[F(5,105)=2.44, p<.05]$, indicating the presence of an $\mathrm{AB}$ effect. Without considering lag 1 performance, mean $\mathrm{T} 2$ detection reached a minimum of $66.1 \%$ at lag 2 , a value significantly below baseline (76.3\%) $[t(21)=3.40, p<.05]$, supporting the claim of an $\mathrm{AB}$ effect in this experiment. The mean $\mathrm{AB}$ magnitude (calculated by subtracting lag 2 hit rate from baseline) was 10.2 percentage points. Performance at lag $1(M=$ $65.0 \%, S E=6.2 \%$ ) was comparable to that at lag 2, indicating an absence of lag 1 sparing. This was supported by a within-participants contrast analysis, which showed the lag effect to be significantly linear in nature $[F(1,21)=$ $6.36, p<.05]$.

\section{Discussion}

The main finding of Experiment 1 was a significant $\mathrm{AB}$ effect when the T1 task required texture element shape discrimination and the $\mathrm{T} 2$ task required detection of a prespecified face. This result contrasts strongly with findings by Awh et al. (2004), who reported no AB effect for faces unless the $\mathrm{T} 1$ task involved configural processing, and by Lavie et al. (2003), who suggested that face processing is obligatory.

Awh et al. (2004) reported no AB for faces unless the $\mathrm{T} 1$ task required configural processing. In our experiment, T1 was clearly a featural, as opposed to configural, task,

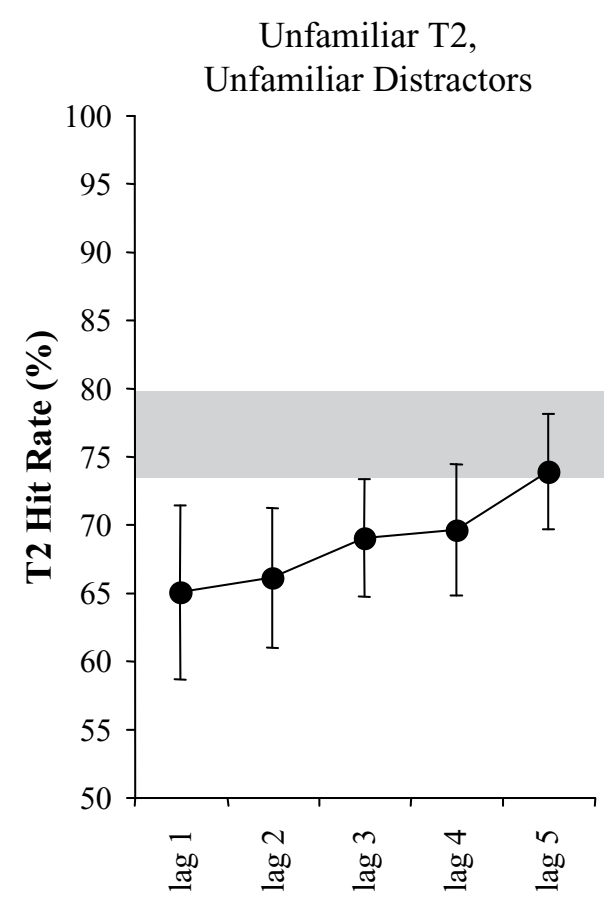

Figure 4. Mean percent hit rate as a function of lag for detection of unfamiliar $\mathrm{T} 2$ faces among unfamiliar distractor faces in Experiment 1. Bars represent $\pm 1 S E$, and the shaded area represents the mean hit rate at baseline $\pm 1 S E$. 
yet we found a robust $A B$ effect. One source of the discrepancy might lie in the operational definition of the $A B$ effect. Awh et al. defined an $A B$ as a significant difference between $\mathrm{T} 2$ performance rates obtained in dual-task trials with those obtained when the T1 task was to be ignored (single-task trials). This makes sense if there is no effect of lag for the single-task condition (indicating that $\mathrm{T} 1 \mathrm{was}$ effectively ignored). Yet, in their critical T1-digit/T2-face experiment (for which they reported no $\mathrm{AB}$ effect), there was a significant effect of lag in both single- and dual-task conditions, suggesting that $\mathrm{T} 1$ was difficult to ignore. This sheds doubt on their claim that an $\mathrm{AB}$ effect was absent. If our definition of an $\mathrm{AB}$ effect (a significant difference in performance for long vs. short lags) is applied to their data, an $\mathrm{AB}$ effect is evident. This observation considerably weakens the basis for their proposal of a special attention mechanism for configural face processing.

These criticisms aside, it is possible that our texture T1 task was configural and that this accounted for the presence of an $A B$ effect in our experiment. We think this is unlikely because we did not find lag 1 sparing in our experiment. The term lag 1 sparing refers to the finding of no obvious perceptual deficit for stimuli presented at lag 1 in an $\mathrm{AB}$ procedure that produces large deficits for the same stimuli presented at lag 2. Lag 1 sparing is generally found to occur when $\mathrm{T} 1$ and $\mathrm{T} 2$ tasks do not require a stimulus category switch (Visser, Bischof, \& Di Lollo, 1999). If our T1 stimuli were somehow face-like or used the same processes as a face identification task (i.e., configural processing), then lag 1 sparing should have been evident. This was not the case. Our result therefore shows that an $\mathrm{AB}$ for faces does not depend on prior engagement of face processing mechanisms and supports the more parsimonious default view that the attention needed for face processing is not particularly different from that required to process any other stimulus. ${ }^{1}$ Existing, nonstimulusspecific accounts of the AB effect (e.g., Shapiro, Arnell, $\&$ Raymond, 1997) appear fully adequate.

The finding of an $\mathrm{AB}$ for faces, indicating that attention is needed for face identification, contrasts with recent findings from a study by Lavie et al. (2003). Their task required participants to search for a famous name among a list of centrally presented words and to categorize the target name as belonging to a pop star or a politician. Famous face distractors, either congruent or incongruent with the target category, were presented as irrelevant flankers. By manipulating the perceptual load of the central task, Lavie et al. expected that a high load would leave no attention for processing the distractor faces. Despite removing attentional resource from the flanker faces, they reported interference effects from these distractors on the name categorization task; this finding could be interpreted as obligatory, attention-free processing for faces. Our finding of an $\mathrm{AB}$ effect for a face identification task is inconsistent with this.

One important difference is that we used unfamiliar faces, whereas Lavie et al. (2003) used famous faces. Extreme stimulus familiarity appears to reduce the need for attention (Buttle \& Raymond, 2003; Shapiro, Caldwell, \& Sorensen, 1997; Tong \& Nakayama, 1999), and this might account for the difference between our findings and Lavie et al.'s findings. In Experiment 2, we explored this possibility with the expectation that, if famous faces were used as $\mathrm{T} 2$ items, $\mathrm{AB}$ effects should be reduced or eliminated.

\section{EXPERIMENT 2}

In Experiment 2, we explored the effect of high familiarity on face detection within the $\mathrm{AB}$. A previous $\mathrm{AB}$ study with personal names (Shapiro, Caldwell, \& Sorensen, 1997) and a visual search study with one's own face (Tong \& Nakayama, 1999) suggested that familiarity with an image reduces the need for attention during processing. Note that both of these studies confounded familiarity with personal social relevance by using the participant's own name or face, making it unclear whether familiarity was the key factor in reducing attentional demand during processing. However, other studies using famous face stimuli (less personally relevant than one's own face) in distractor interference (Jenkins, Lavie, \& Driver, 2003; Lavie et al., 2003) and change detection paradigms (Buttle \& Raymond, 2003) provide evidence that familiarity reduces the need for attention in face processing. If so, then $\mathrm{AB}$ effects should be minimal for highly familiar faces.

To test this, we presented as T2 two famous British males, Tony Blair (Prime Minister at the time of study) and Charles Windsor, the Prince of Wales. Two groups of participants were tested: a "British" (GB) group and an "other European" (OE) group (the OE group excluded United Kingdom [U.K.] and Republic of Ireland citizens). The GB participants were expected to have very high familiarity with these faces and show no $\mathrm{AB}$, whereas the OE participants were expected to be less familiar and produce an AB effect. Note that Tong and Nakayama (1999) claimed that the benefits of familiarity for attention can come about only with extreme familiarity and cannot be produced even when participants receive thousands of exposures to a face. Their speeded search effects were found only for one's own face and not with merely familiar, recently learned faces. Similarly, in the Shapiro, Caldwell, and Sorensen (1997) study, common, familiar names were used as T2 stimuli, but only when the name was the participant's own did it fail to produce an AB. In the present experiment, the participants in the $\mathrm{OE}$ group were expected to recognize the famous faces we used, but they were not expected to have the same level of extreme familiarity that the GB participants would have. Our between-groups experimental design allowed us to control for the contribution of stimulus artifacts driving T2 detection. The method was as outlined in the General Method section with the following exceptions.

\section{Method}

Participants. The participants recruited for the GB group were U.K. citizens and had spent at least the past 5 years living in the U.K. The participants recruited for the OE group had all been born 
and raised in continental Europe and had been living in the U.K. for less than 1 year. They were citizens from Italy, Spain, Germany, Greece, France, and Norway. One OE participant was excluded because of a high FA rate. Interestingly, 9 GB participants and $5 \mathrm{OE}$ participants had mean T2 hit rates greater than $98 \%$, rendering their data uninterpretable. Excluding these, data were obtained from 16 GB participants ( 9 females, 7 males; mean age 22 years) and $12 \mathrm{OE}$ participants ( 7 females, 5 males; mean age 22 years).

Stimuli. The T2 items, an image of Tony Blair and an image of Prince Charles, were grayscale photographs similar to the other faces stimuli (as described in the General Method section). As in Experiment 1, all T2 masks and T2 fillers depicted men matched in apparent age to each T2 face. These and all distractors were unfamiliar faces.

Procedure. Each participant was tested in two blocks, one block for each of the famous faces as T2 (counterbalanced). Before the experiment began, the participants rated their familiarity for the written names of each T2 stimulus, along with 24 other famous and nonfamous names (using a scale of $0-5 ; 0=$ no name recognition, $5=$ high familiarity). The participants were also asked to name each $\mathrm{T} 2$ face on completion of both experimental blocks.

\section{Results}

T1 task. Group mean percent correct $\mathrm{T} 1$ responses were $97.2 \%(S E=0.5 \%)$ and $97.3 \%(S E=0.8 \%)$ for Groups GB and $\mathrm{OE}$, respectively, a nonsignificant group difference.

Familiarity ratings. Familiarity ratings for the T2 names provided by Group GB $(M=4.8, S E=0.2)$ were only marginally greater, and not significantly so, than those provided by Group OE $(M=4.5, S E=0.2)$. After completing the experiment, all GB participants correctly named each T2 face, whereas 3 OE participants made errors. These participants were still included in the analysis.

T2 performance. The mean FA rates for Groups GB and $\mathrm{OE}$ were $6.8 \%(S E=0.9 \%)$ and $5.0 \%(S E=1.0 \%)$, respectively, a nonsignificant group difference. The mean T2 hit rate for each group is plotted as a function of lag in Figure 5. There are two points to note. First, no AB effect was found for Group GB (Figure 5A), a finding that contrasts with the $\mathrm{AB}$ effect observed for a similar group of participants using an unfamiliar T2 face in Experiment 1. Second, an AB effect was clearly evident in the data from the participants of Group OE (Figure 5B), even though they saw the same faces as the participants of Group GB.A mixed-design ANOVA with group (GB, OE) as a betweenparticipants factor and lag $(1,2,3,4,5$, and baseline) as a within-participants factor confirmed that the interaction of lag $\times$ group was significant $[F(5,130)=2.76, p<$ $.05]$. While the main effect of lag was nonsignificant for Group GB $(F<1.0)$, the lag effect was highly significant for Group $\mathrm{OE}[F(5,55)=5.09, p<.01]$ and significantly cubic in nature $[F(1,11)=17.90, p<.01]$. There was also a significant main effect of group $[F(1,26)=4.93, p<$ $.05]$, with Group OE performing overall more poorly than Group GB. For Group GB, the performance minimum seen at lag 3 was very high $(91.3 \%)$ and did not differ from baseline performance (91.4\%). However, for Group OE, a performance minimum of $78.7 \%$ was observed at lag 2 , which was marginally significantly different from
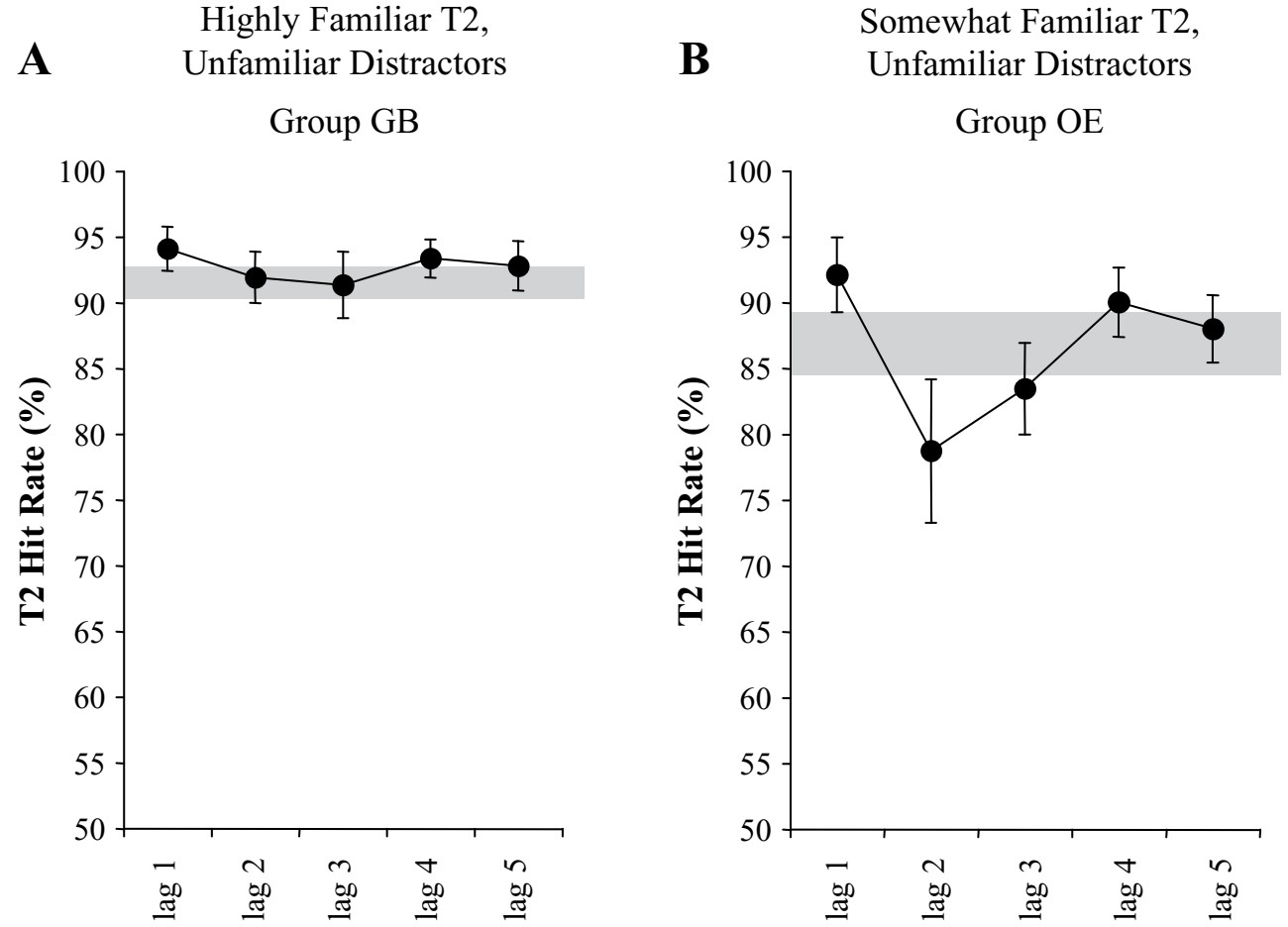

Figure 5. Mean percent hit rate as a function of lag in Experiment 2. (A) Detection of highly familiar T2 faces among unfamiliar distractor faces, Group GB (British). (B) Detection of somewhat familiar T2 faces among unfamiliar distractor faces, Group OE (other Europeans). Bars represent $\pm 1 S E$, and the shaded area represents the mean hit rate at baseline $\pm 1 S E$. 
baseline $(86.5 \%)[t(11)=1.90, p=.08]$. The AB magnitude values calculated for the GB and OE groups were 0.1 and 7.8 percentage points, respectively, a marginally significant difference $[t(26)=1.8, p=.09]$.

\section{Discussion}

An important feature of the experimental design used here was that the same $\mathrm{T} 2$ faces were tested for all participants. Only the presumed familiarity of the participants with those images differed. Thus, we can be confident that group differences in $\mathrm{T} 2$ detection were not due to featural artifacts in the images used. The pattern of $\mathrm{AB}$ effects reported here ( $\mathrm{AB}$ absent for the $\mathrm{GB}$ group; $\mathrm{AB}$ present for the $\mathrm{OE}$ group) suggests that, despite similar subjective ratings of familiarity for both groups, visual experience with specific faces determines the amount of attentional processing needed for rapid identification.

There was one notable difference between the $\mathrm{AB}$ effect for unfamiliar T2 faces (Experiment 1) and that for somewhat familiar T2 faces (Group OE, Experiment 2). Whereas lag 1 sparing was absent in Experiment 1, it was present in the OE group. Experiments 1 and 2 comprised identical T1-T2 category switches (i.e., the attentional system had to reconfigure from abstract image to face image), so the presence of lag 1 sparing in Group OE is surprising. This leads to the possibility that an additional moderator of lag 1 sparing may exist, one that is connected to the familiarity of the T2 item immediately following T1. Some degree of familiarity with the T2 face in Group OE might have allowed it to be rapidly or distinctively encoded so that, when attentional selection was applied to T1 and its mask (being T2 at lag 1), T2's representation was not confused with T1 and its detection was facilitated. When T2 (at lag 1) was an unfamiliar face, encoding might have been more time consuming or resulted in a less robust, less distinct representation, reducing the likelihood of conscious awareness for it.

Our main goal in Experiment 2 was to determine the effect of high familiarity for $\mathrm{T} 2$ faces on the $\mathrm{AB}$ effect. Therefore, an important comparison lies between Experiment 1 (an AB was found) and Group GB (no AB effect). A mixed-design ANOVA using group (unfamiliar T2 vs. highly familiar T2) as a between-participants factor and lag $(1,2,3,4,5$, and baseline) as a within-participants factor revealed a marginally significant interaction of lag $\times$ group $[F(5,180)=2.01, p=.08]$. An independent $t$ test comparing $\mathrm{AB}$ magnitude values for each condition confirmed a significantly greater dual-task cost for an unfamiliar T2 face (10.2 percentage points) than for a famous $\mathrm{T} 2$ face $(0.1$ percentage points) $[t(36)=2.53, p<.05]$.

\section{EXPERIMENT 3}

Although the results of Experiment 2 suggest that high familiarity provides protection from the consequences of the $\mathrm{AB}$ bottleneck, an alternative interpretation is that the stimulus conditions (for Group GB) might have allowed a semantic pop-out effect for T2, whereas those in Experiment 1 did not. Perhaps a highly familiar T2 face among unfamiliar distractor faces is easy to detect because of its uniqueness, rather than because of familiarity per se. Indeed, Barnard et al. (2004) provided evidence that distractors semantically unrelated to targets within an RSVP stream caused less interference with target identification (i.e., produced a smaller $\mathrm{AB}$ effect) than did distractors of a high semantic relation to targets. To determine whether distinctiveness of the T2 item could account for the absence of an AB effect in Group GB (Experiment 2), in Experiment 3, we replaced unfamiliar distractors with famous face distractors in the RSVP stream and presented either unfamiliar or highly familiar (famous) faces as T2 items. An unfamiliar T2 face among highly familiar distractors created a pop-out condition in which $\mathrm{T} 2$ was unique in its lack of familiarity. A highly familiar T2 face among highly familiar distractors created a stimulus configuration in which pop-out was absent.

Using only British participants and only highly familiar distractors, we asked one group of participants to detect unfamiliar T2 faces (Group U-F) and another to detect highly familiar T2 faces (Group F-F). (We used the same T2 faces that were tested previously in Experiments 1 and 2.) We rename the group from Experiment 1 as $\mathrm{U}-\mathrm{U}$, and Group GB from Experiment 2 as F-U. Thus we have in total, across our three experiments, four groups fully crossed for T2 familiarity (highly familiar, unfamiliar) and distractor familiarity (highly familiar, unfamiliar), where $\mathrm{F}=$ familiar and $\mathrm{U}=$ unfamiliar; the first letter refers to the $\mathrm{T} 2$ stimulus, and the second letter refers to the distractor stimuli. If familiarity modulates the $\mathrm{AB}$, then, in Experiment 3, no $A B$ effect should be found when $T 2$ is a famous face (Group F-F), and an AB should be present when $\mathrm{T} 2$ is an unfamiliar face (Group U-F). If, on the other hand, pop-out explains the lack of $\mathrm{AB}$ effect in Group F-U in Experiment 2, then only when distractors and $\mathrm{T} 2$ match on a familiarity dimension (Group F-F) should we see an $\mathrm{AB}$ effect. The predicted and actual results from all three experiments are summarized in Table 1.

\section{Method}

Participants. All participants were U.K. citizens and had spent at least the past 5 years living in the U.K. They were randomly assigned to one of two groups ( $\mathrm{U}-\mathrm{F}$ or F-F). Unexpectedly, a large number of participants in Group U-F had extremely high FA rates. In 14 cases (39\%), this was greater than $20 \%$, so data from these participants were excluded. High FA rates might have resulted because the high

Table 1

Predicted and Actual Attentional Blink (AB) Results Relative to the Pop-Out and Familiarity Accounts for Each Group

\begin{tabular}{clll}
\hline & \multicolumn{2}{c}{ Prediction } & \\
\cline { 2 - 3 } Group & Pop-Out & Familiarity & Result \\
\hline U-U & AB & AB & AB \\
F-U & No AB & No AB & No AB \\
U-F & No AB & AB & AB \\
F-F & AB & No AB & No AB \\
\hline
\end{tabular}

Note-U-U, unfamiliar T2, unfamiliar distractors (Experiment 1). F-U, familiar T2, unfamiliar distractors (Group GB, Experiment 2). U-F, unfamiliar T2, familiar distractors (Experiment 3). F-F, familiar T2, familiar distractors (Experiment 3). 
familiarity of the faces used in the distractor stream induced a generalized, false sense of recognition of the unfamiliar T2 faces. Only 5 participants (19\%) from Group F-F were excluded on this basis, a percentage comparable to that found in Experiment 1 (15\%). After exclusions, data were analyzed from 22 participants ( 12 females, 10 males; mean age 22 years) and 21 participants ( 14 females, 7 males; mean age 23 years) in Groups $\mathrm{U}-\mathrm{F}$ and F-F, respectively.

Stimuli and Procedure. To maintain consistency across experiments, T2 images were the two unfamiliar T2 faces used in Experiment 1 and the two famous T2 faces used in Experiment 2. Of the famous distractor faces, half were male and half were female. Five were British politicians, 6 were from the British Royal Family (politicians and royalty were never used as T2 masks), and the remainder were a mixture of actors, singers, sports stars, and models considered internationally famous. Within each condition, the experiment was split into two blocks, one for each face (counterbalanced), and the procedure was as described in the General Method section.

On completion of the experiment, each participant rated $\mathrm{T} 2$ and distractor faces for familiarity. Each face used in the experiment was presented in the center of a computer screen, and the participants were required to make a familiarity judgment based on a scale of $0-5$ ( 0 indicating no recognition of the face, and 5 indicating high familiarity). The participants in Group F-F were also asked to name each $\mathrm{T} 2$ face as a further check of recognition.

\section{Results}

T1 task. The mean percent correct $\mathrm{T} 1$ response in Group U-F was $96.4 \%(S E=0.7 \%)$, a value not statistically different from that in Group F-F $(M=96.4 \%, S E=0.6 \%)$.

Familiarity ratings. Familiarity ratings for the unfamiliar T2 faces in Group U-F $(M=1.91, S E=0.20)$ were significantly lower than ratings for the famous T2 faces in
Group F-F $(M=4.81, S E=0.07 ; U=0.50, p<.01)$. Familiarity ratings in Group U-F for the famous distractors $(M=3.56, S E=0.12)$ were not significantly different from those obtained from Group F-F $(M=3.44, S E=$ $0.15)$. All participants in Group F-F correctly named each famous T2 face.

T2 performance. The $\mathrm{FA}$ rates were $8.5 \%(S E=$ $1.0 \%)$ and $8.2 \%(S E=1.0 \%)$ in Groups U-F and F-F, respectively, and did not differ statistically. Mean T2 hit rates for each group are plotted as a function of lag in Figure 6. For Group U-F (Figure 6A), a repeated measures ANOVA with lag $(1,2,3,4,5$, and baseline) as a withinparticipants factor revealed a significant main effect of $\operatorname{lag}[F(5,105)=3.11, p<.05]$, indicating the presence of an $\mathrm{AB}$ effect. Performance reached a minimum of $73.1 \%$ at lag 2 and improved with longer lags to reach a baseline value of $82.0 \%$. The difference between these values was significant $[t(21)=3.31, p<.05]$, thereby confirming a clear $\mathrm{AB}$ effect. The $\mathrm{AB}$ magnitude value obtained in Group U-F (8.9 percentage points) did not differ significantly from the $\mathrm{AB}$ magnitude value obtained from Group U-U (10.2 percentage points) in Experiment 1. Unlike the $A B$ function obtained for Group U-U, performance of Group U-F at lag 1 was not significantly different from baseline $(p>.1)$, normally indicating lag 1 sparing. However, a within-participants contrast analysis revealed that the main effect of lag was significantly linear in nature $[F(1,21)=5.19, p<.05]$, suggesting that lag 1 sparing, if present, was negligible.
A Unfamiliar T2, Familiar Distractors

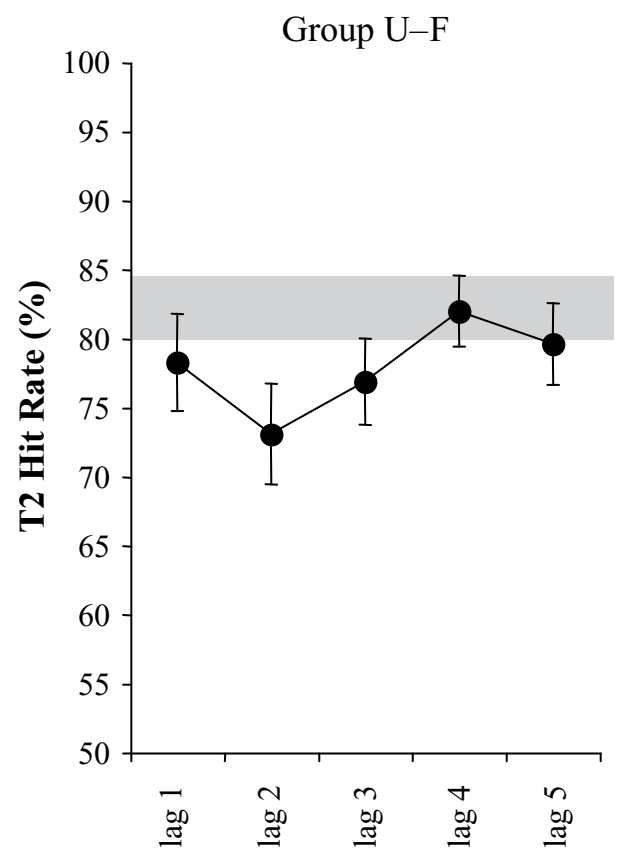

B Familiar T2, Familiar Distractors

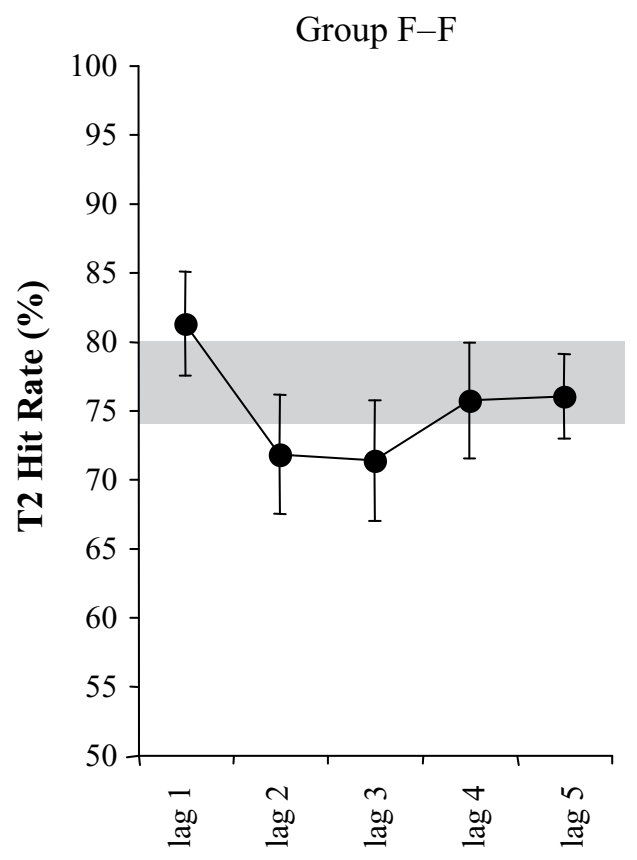

Figure 6. Mean percent hit rate as a function of lag in Experiment 3. (A) Detection of unfamiliar T2 faces among highly familiar distractor faces, Group U-F. (B) Detection of highly familiar T2 faces among highly familiar distractor faces, Group $F-F$. Bars represent $\pm 1 S E$, and the shaded area represents the mean hit rate at baseline $\pm 1 S E$. 
In contrast to Group U-F, the detection of highly familiar T2 faces in a stream of other highly familiar faces (Group F-F, Figure 6B) showed no AB. Statistically, the main effect of lag was significant for this group $[F(5,100)=2.75$, $p<.05]$, but this result was influenced by performance at lag $1(82.2 \%)$, which was marginally significantly higher than baseline $(77.0 \%)[t(20)=1.93, p=.07]$. With lag 1 data excluded, there was a nonsignificant main effect of lag. ${ }^{2}$ Performance reached a minimum of $72.3 \%$ at lag 3, but this value was not significantly different from baseline. AB magnitude in Group F-F (4.7 percentage points) did not differ significantly from the AB magnitude value obtained from Group F-U in Experiment 2 (0.1 percentage points). The AB magnitudes obtained in all four groups are shown in Figure 7A.

\section{Discussion}

For Group U-F, there was clear evidence of an AB effect that was largely similar to that obtained in Experiment 1 (Group U-U); for Group F-F, there was no evidence of an AB effect, a result that mirrors that found for Group F-U (Experiment 2). Taken together, these findings indicate that, regardless of distractor type, when T2 was highly familiar, it appeared protected from the AB bottleneck, but when it was unfamiliar, an AB effect was found. These results rule out the possibility that uniqueness of the T2 item relative to distractor faces on a familiarity dimension accounts for why perception of highly familiar faces appears to be unperturbed by an immediate prior task.

To support these statements, we conducted analyses using data from all four groups (U-U, F-U, U-F, and F-F). A mixed-design ANOVA using T2 type (unfamiliar vs. highly familiar) and RSVP configuration (pop-out vs. no pop-out) as between-participants factors and lag $(1,2$, $3,4,5$, and baseline) as a within-participants factor was conducted on the hit rates obtained from each participant. Supporting the possibility that T2 familiarity modulates the $\mathrm{AB}$, we found a significant interaction between lag and T2 type $[F(5,385)=3.14, p=.01]$, coupled with a nonsignificant interaction of lag $\times$ RSVP configuration $(F<1.0)$. Critically, the triple interaction of lag $\times$ T2 type $\times$ RSVP configuration was also nonsignificant $[F(5,385)=1.41, p>.1]$.

These data are perhaps better summarized using the AB magnitude measure. We repeated the cross-experimental analysis using a univariate ANOVA on individual AB magnitude data with T2 type (unfamiliar vs. highly familiar) and RSVP configuration (pop-out vs. no pop-out) as between-participants factors. We found a significant main effect of T2 type $[F(1,77)=6.83, p=.01]$, with an $\mathrm{AB}$ magnitude for unfamiliar $\mathrm{T} 2$ faces $(9.5$ percentage points) three and a half times larger than that for highly familiar T2 faces (2.7 percentage points) (Figure 7B). Both the main effect of RSVP configuration and the interaction between T2 type and RSVP configuration were nonsignificant.

Similar cross-experimental analyses conducted on T1 percent correct data and FA rates showed that, in all cases, the main and interaction effects were nonsignificant, indi-
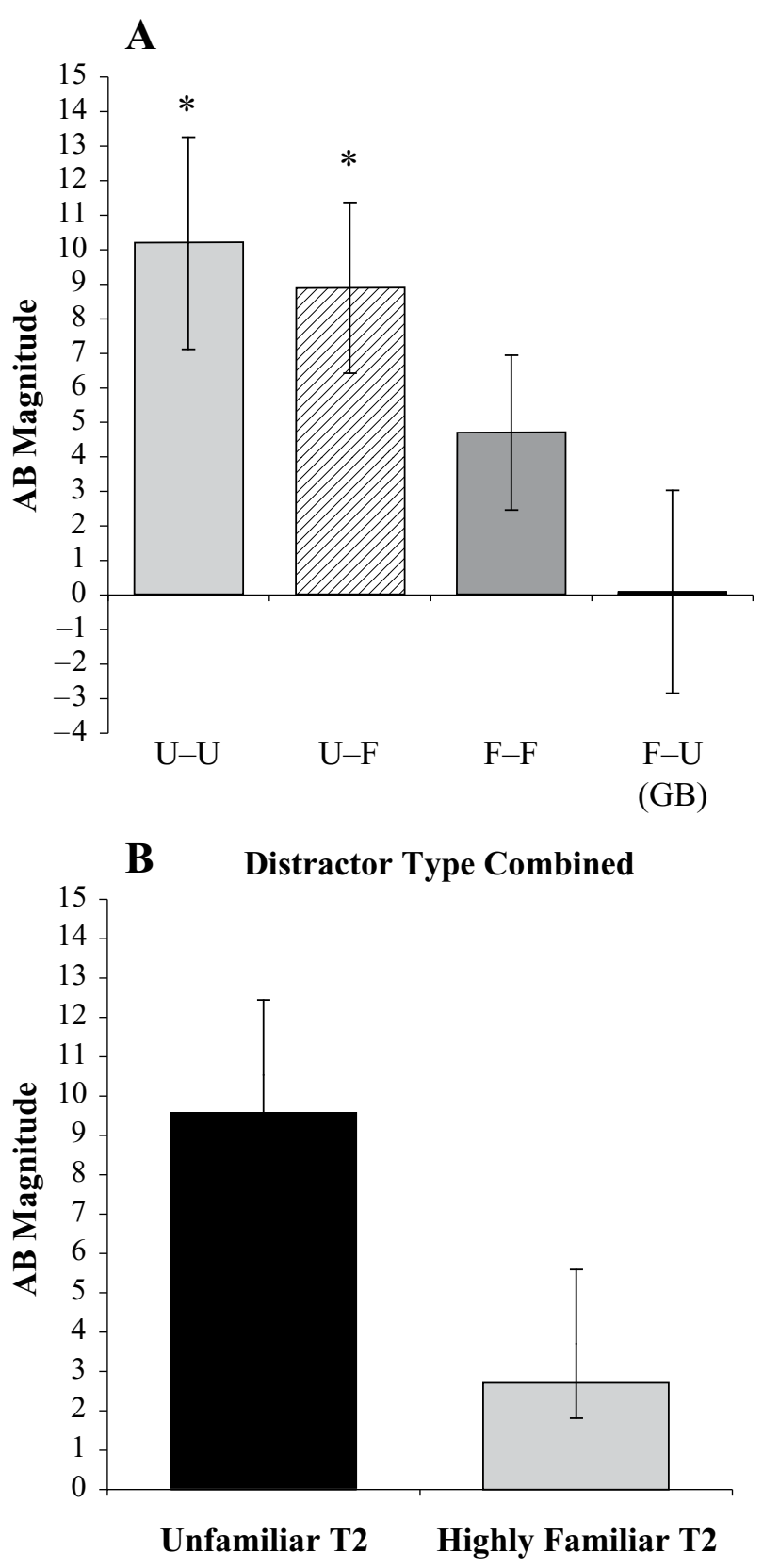

Figure 7. Attentional blink (AB) magnitude values. (A) Each of the four groups: $\mathbf{U}-\mathbf{U}$ (Experiment 1); F-U (GB) (Experiment 2); and $U-F$ and $F-F$ (Experiment 3). The first letter ( $U$ or $F$ ) refers to the $T 2$ item, and the second letter ( $U$ or $F)$ refers to the distractor item, where $U$ indicates unfamiliar faces and $F$ indicates (highly) familiar faces. An asterisk indicates a significant $A B$ effect, whereas the absence of an asterisk indicates there was no significant $A B$ effect. (B) Unfamiliar and highly familiar $T 2$ faces collapsed across distractor type. Bars represent $\pm 1 S E$.

cating that neither processing demands of the T1 task nor guess rates on the T2 task could account for the effect of $\mathrm{T} 2$ familiarity on the AB.

One notable feature of the results from Group F-F is that overall performance on the $\mathrm{T} 2$ task was markedly re- 
duced relative to that of Group $\mathrm{F}-\mathrm{U}$. This reduction in performance might have been caused by a general increase in task difficulty produced when the highly familiar T2 face had to be distinguished from equally highly familiar distractors. However, this effect was not lag dependent and does not therefore appear to have an attentional basis.

\section{GENERAL DISCUSSION}

In three experiments, we asked participants to discriminate the texture of an abstract pattern (T1) and to detect the presence of a specific face (T2), embedded in a series of rapidly presented distractor faces. In Experiment 1, all faces (both T2 and distractor) were unfamiliar (i.e., unknown to the participants prior to the experiment), and an $\mathrm{AB}$ effect was found. In Experiment 2, the distractor faces remained unfamiliar, but the $\mathrm{T} 2$ faces used were highly familiar to one group of participants and only somewhat familiar to another group. No AB effect was observed when T2 was highly familiar, but an AB effect was observed when T2 was somewhat familiar. Because the same T2 faces were used for both groups, the AB effect for somewhat familiar faces provides strong evidence against the argument that stimulus artifacts in the T2 stimuli could explain the lack of $\mathrm{AB}$ for highly familiar faces. In Experiment 3, we examined whether stimulus uniqueness (i.e., the potential for T2 to pop out of the RSVP display) could account for the lack of AB observed for highly familiar faces. In Experiment 3, all distractor faces were highly familiar faces and the T2 faces were either unfamiliar or highly familiar. We found an AB effect for unfamiliar T2 faces and no $\mathrm{AB}$ for highly familiar $\mathrm{T} 2$ faces, replicating the results obtained in Experiments 1 and 2 and illustrating that pop-out cannot account for any lack of $\mathrm{AB}$ observed.

We interpret the pattern of results across these experiments to support two main conclusions. First, we conclude that unfamiliar faces require attention if their identity is to gain access to awareness. Moreover, our results provide no compelling reason to suppose that the attentional resources needed for attending faces is qualitatively different from that needed for attending any other stimuli. Second, we conclude that high familiarity reduces the amount of attentional resource required for successful face identification. We deal with each point separately.

\section{Faces and Attention}

Our results refute the proposal that face identification per se requires no attention (e.g., Farah, Wilson, et al., 1995; Lavie et al., 2003). Clearly, finding an AB effect for unfamiliar and somewhat familiar faces is evidence of an attentional requirement for the conscious awareness of face identification. Studies have shown that face information (especially emotional expression information) subliminally presented (Dimberg, Thunberg, \& Elmehed, 2000) or presented outside the focus of attention (Eastwood, Smilek, \& Merikle, 2001) can implicitly influence behavior and cause emotion-specific brain activation (Anderson, Christoff, Panitz, De Rosa, \& Gabrieli, 2003; Vuilleumier et al., 2001; Whalen et al., 1998; but see also
Holmes, Vuilleumier, \& Eimer, 2003, Pessoa, Kastner, \& Ungerleider, 2002, and Pessoa, McKenna, et al., 2002, for contradictory results). However, evidence that face identification can modify behavior without explicit recognition has been obtained only using famous faces (Buttle \& Raymond, 2003; Jenkins et al., 2003; Lavie et al., 2003). As our data suggest, such phenomena probably stem from stimulus familiarity and are unlikely to be indicative of general face processing mechanisms.

Our results also provide no support for the notion of a special attentional mechanism dedicated to either face or configural processing (Awh et al., 2004; Jenkins et al., 2003; Palermo \& Rhodes, 2002). The special-attention view of face processing posits that configural processing, thought to be required for optimal face identification, requires a separate attentional resource, one that is not used for featural, nonface stimuli. On the basis of results from AB experiments using digits, letters, faces, and greebles (complex, volumetric figures that have been shown to engage configural processing once expertise with such stimuli is achieved), Awh et al. concluded that only when identification of T1 used configural processing, and hence depleted a hypothetical configural attention channel, would an AB effect be observed for face T2 stimuli. Contrary to this, using an obviously featural T1 task, we found clear evidence of an AB effect for faces. Our results showed that explicit face identification requires similar attentional resource as that required for processing nonface, featural stimuli.

As discussed in Experiment 1, the discrepancy between our results and those of Awh et al. (2004) most likely results from differences in how an $A B$ is operationally defined rather than differences in actual findings. If the data from Awh et al.'s Experiment 5 (T1 digit/T2 face) are used to estimate an $\mathrm{AB}$ magnitude value (i.e., accuracy at lags beyond $500 \mathrm{msec}$ minus the minimum lag accuracy), the dual-task cost is about 10 percentage points, a value similar to the AB magnitude value we obtained for unfamiliar T2 faces. They also found a significant main effect of lag in this critical experiment. Therefore, their results seem to indicate an AB effect for a T2 face when T1 was a digit, a conclusion at odds with their proposal of a special configural attention channel. Certainly it lacks parsimony to propose a special attentional mechanism for faces, or face-like, stimuli, and our results provide empirical evidence against this notion. Instead, our results support the default view of attentional allocation for face processing: Perceptual and cognitive processes needed for identification of faces are susceptible to a temporal bottleneck in attention in much the same way as other nonface stimuli.

We did not measure $A B$ effects for nonface stimuli in this study, so we cannot directly compare, either qualitatively or quantitatively, the attention needed for face versus nonface object identification. However, our AB function for unfamiliar faces (Experiment 1) was qualitatively consistent with $\mathrm{AB}$ functions obtained previously using nonface objects (e.g., Raymond, 2003). Parsimony thus eliminates any need to posit a special attentional mechanism for faces on the basis of the current data. 


\section{Familiarity and Face Processing}

The second main conclusion that can be drawn from our findings is that highly familiar (famous) faces appear to be processed with less attention than do unfamiliar faces. This is consistent with several previous findings. Irrelevant famous face distractors caused interference effects on a difficult attention-demanding central namecategorization task (Jenkins et al., 2003; Lavie et al., 2003); performance on a change detection task was better with famous faces than with unfamiliar faces (Buttle \& Raymond, 2003); and visual search for one's own face was more efficient than search for a recently learned stranger's face (Tong \& Nakayama, 1999). An important question regarding all these studies is whether the effects of high familiarity are special to face stimuli or are general phenomena of familiar stimuli.

Contrary to the faces-are-special view, the latter seems a more likely possibility. In a brain imaging study, GornoTempini and Price (2001) used famous faces and buildings as stimuli and found that fame-specific activations in the medial temporal gyrus were unaffected by stimulus category. Moreover, several experiments have shown an attentional independence for the recognition of one's own name, a highly familiar nonface stimulus. In these studies, repetition blindness (Arnell, Shapiro, \& Sorensen, 1999), inattentional blindness (Mack \& Rock, 1998), and AB (Shapiro, Caldwell, \& Sorensen, 1997) paradigms were used. The latter study is nicely comparable to ours, and the similarity in findings strongly suggests that famous faces "escaped" the AB in our study because of their high familiarity, not their stimulus class. Importantly, our finding that high familiarity with a face allows identification to proceed with little attention resolves some of the seemingly conflicting results about the role of attention in face processing. It points out that empirical results obtained with famous faces cannot be used to make general statements about the role of attention in face processing.

Why are highly familiar faces protected from the $\mathrm{AB}$ effect? If a T2 stimulus is to gain access to awareness and be reportable at the end of an RSVP trial, its representation must be durably stored in WM. Our finding that highly familiar faces escaped the AB suggests two possibilities. First, highly familiar faces might be encoded more quickly than less familiar ones, making their representations less susceptible to integration masking by the immediately succeeding stimulus and more likely to gain access to WM. Tong and Nakayama (1999) suggested that very large numbers of repeated (and probably different) exposures to a face might lead to specific pruning of low-level sensory processes used to identify the stimulus, allowing only sensory information that is diagnostic for identification to be processed at a higher level (Barlow, 1961). They proposed that efficient, sparse use of neural resources could create a "compact visual code" for previously encountered faces, making processing faster. Perhaps, in a dual-task RSVP context, this would make them resistant to masking effects. In this sense, compact visual codes could have consequences for the efficiency of transfer of informa- tion into WM. To the extent that selective attention is used to bind featural information together (Luck \& Beach, 1998; Treisman, 1996) and then transfer it as a meaningful chunk into WM, the availability of any early sensory grouping processes would ease the need for attention. Extreme familiarity might minimize reliance on attention for transfer of information into WM and thus allow highly familiar stimuli to escape the AB. However, this hypothetical advantage in sensory processing is not supported empirically as yet by brain imaging studies. N170 waveform activity, thought to be indicative of early structural encoding of faces (Bentin et al., 1996), was not speeded or diminished by familiarity with a face (e.g., Bentin \& Deouell, 2000), an effect expected if familiarity enhanced compaction of structural face information. Moreover, activity levels in the FFA do not appear to be obviously affected by familiarity (GornoTempini \& Price, 2001; Shah et al., 2001; but see Leveroni et al., 2000, for contrasting results), again suggesting that basic encoding of face information might not be aided by familiarity.

A second possibility is that significant perceptual experience with a stimulus might allow rapid, "attentionfriendly" maintenance of a distinct, durable representation within WM, once entry has been gained. Highly familiar faces might be more robustly or distinctively retained in WM (i.e., their representations might be less likely to suffer from decay or interference than might less familiar faces). Cowan (2001) suggested that the persistence of representations in WM is enhanced by strong long-term memory (LTM) representations. Given that a highly familiar face is more richly encoded in LTM than is a less familiar face, then familiar face representations should be less likely to decay before their report is required or be less affected by interference from distractor items. Such ideas are supported by brain imaging studies that showed that famous faces, unlike unfamiliar faces, activated regions of the posterior cingulate, including the retrosplenial cortex, areas associated with episodic memory, familiarity, and emotional salience (e.g., Shah et al., 2001), and areas of the left anterior middle temporal gyrus (Gorno-Tempini $\&$ Price, 2001), that are associated with semantic processing and categorization (e.g., Devlin et al., 2002). Further support for a late, postperceptual familiarity influence is provided by studies that demonstrated an effect of face familiarity on later ERP components: Enhanced negativity of the N400 waveform has been reported for familiar faces, relative to unfamiliar faces (e.g., Bentin \& Deouell, 2000; Eimer, 2000), an effect considered to reflect semantic activity involved in the identification of familiar faces. In our study, we could not distinguish between these alternatives of an early versus late influence of familiarity, but we do provide a behavioral rationale for a search to uncover the brain mechanisms that allow high familiarity to ease visual cognition.

In conclusion, our findings indicate that identification of unfamiliar faces requires attentional resource, probably in much the same way as other nonface stimuli. We found no support for the notion that a dedicated config- 
ural attentional channel mediates face identification (Awh et al., 2004; Palermo \& Rhodes, 2002). However, our results indicate that high familiarity significantly reduces the need for attention during face identification. Perhaps highly familiar stimuli, such as famous faces and probably other well-known nonface stimuli, are protected from $\mathrm{AB}$ effects because they benefit from enduring, stable, and highly resilient representations in WM, aided by LTM stores. Creation of such exceptional WM representations appears to be highly efficient, and they require little attentional resource.

\section{REFERENCES}

Anderson, A. K., Christoff, K., Panitz, D., De Rosa, E., \& GabriELI, J. D. E. (2003). Neural correlates of the automatic processing of threat facial signals. Journal of Neuroscience, 23, 5627-5633.

Arnell, K. M., \& Joliceeur, P. (1999). The attentional blink across stimulus modalities: Evidence for central processing limitations. Journal of Experimental Psychology: Human Perception \& Performance, 25, 630-648.

Arnell, K. M., Shapiro, K. L., \& Sorensen, R. E. (1999). Reduced repetition blindness for one's own name. Visual Cognition, 6, 609-635.

Awh, E., Serences, J., Laurey, P., Dhaliwal, H., VAn Der Jagt, T., \& DASSONVILlE, P. (2004). Evidence against a central bottleneck during the attentional blink: Multiple channels for configural and featural processing. Cognitive Psychology, 48, 95-126.

BARLOW, H. B. (1961). The coding of sensory messages. In W. H. Thorpe \& O. L. Zangwill (Eds.), Current problems in animal behaviour (pp. 331-360). Cambridge: Cambridge University Press.

Barnard, P. J., Scott, S., TAylor, J., May, J., \& Knightley, W. (2004). Paying attention to meaning. Psychological Science, 15, 179-186.

Bartlett, J. C., \& Searcy, J. (1993). Inversion and configuration of faces. Cognitive Psychology, 25, 281-316.

Bentin, S., Allison, T., Puce, A., Perez, E., \& McCarthy, G. (1996). Electrophysiological studies of face perception in humans. Journal of Cognitive Neuroscience, 8, 551-565.

Bentin, S., \& Deouell, L. Y. (2000). Structural encoding and identification in face processing: ERP evidence for separate mechanisms. Cognitive Neuropsychology, 17, 35-54.

Boutet, I., Gentes-Hawn, A., \& Chaudhuri, A. (2002). The influence of attention on holistic face encoding. Cognition, 84, 321-341.

Brown, V., Huey, D., \& Findlay, J. M. (1997). Face detection in peripheral vision: Do faces pop out? Perception, 26, 1555-1570.

Buttle, H., \& RAYmond, J. E. (2003). High familiarity enhances visual change detection for face stimuli. Perception \& Psychophysics, 65, 1296-1306.

Carey, S., \& Diamond, R. (1994). Are faces perceived as configurations more by adults than by children? Visual Cognition, 1, 253-274.

Chun, M. M., \& PotTer, M. C. (1995). A two-stage model for multiple target detection in rapid serial visual presentation. Journal of Experimental Psychology: Human Perception \& Performance, 21, 109-127.

Cowan, N. (2001). The magical number 4 in short-term memory: A reconsideration of mental storage capacity. Behavioral \& Brain Sciences, 24, 87-185.

De Renzi, E. (1997). Prosopagnosia. In T. E. Feinberg \& M. J. Farah (Eds.), Behavioral neurology and neuropsychology (pp. 245-255). New York: McGraw-Hill.

Devlin, J. T., Russell, R. P., Davis, M. H., Price, C. J., Moss, H. E., FADILI, M. J., \& TYLER, L. K. (2002). Is there an anatomical basis for category-specificity? Semantic memory studies in PET and fMRI. Neuropsychologia, 40, 54-75.

DiAMOND, R., \& CAREY, S. (1986). Why faces are and are not special: An effect of expertise. Journal of Experimental Psychology: General, 115, 107-117.

Dimberg, U., Thunberg, M., \& Elmehed, K. (2000). Unconscious facial reactions to emotional facial expressions. Psychological Science, 11, 86-89.

Downing, P. E., LiU, J., \& Kanwisher, N. (2001). Testing cognitive models of visual attention with fMRI and MEG. Neuropsychologia, 39, 1329-1342.

Eastwood, J. D., Smilek, D., \& Merikle, P. M. (2001). Differential attentional guidance by unattended faces expressing positive and negative emotion. Perception \& Psychophysics, 63, 1004-1013.

EImer, M. (2000). Event-related brain potentials distinguish processing stages involved in face perception and recognition. Clinical Neurophysiology, 111, 694-705.

FARAH, M. J. (1996). Is face recognition "special"? Evidence from neuropsychology. Behavioural Brain Research, 76, 181-189.

Farah, M. J., TAnaka, J. W., \& Drain, M. (1995). What causes the face inversion effect? Journal of Experimental Psychology: Human Perception \& Performance, 21, 628-634.

Farah, M. J., Wilson, K. D., Drain, H. M., \& TanaKa, J. R. (1995). The inverted face inversion effect in prosopagnosia: Evidence for mandatory, face-specific perceptual mechanisms. Vision Research, 35, 2089-2093.

Folk, C. L., Leber, A. B., \& Egeth, H. E. (2002). Made you blink! Contingent attentional capture produces a spatial blink. Perception \& Psychophysics, 64, 741-753.

Gauthier, I., Skudlarski, P., Gore, J. C., \& Anderson, A. W. (2000). Expertise for cars and birds recruits brain areas involved in face recognition. Nature Neuroscience, 3, 191-197.

GAUTHIER, I., \& TARR, M. J. (2002). Unraveling mechanisms for expert object recognition: Bridging brain activity and behavior. Journal of Experimental Psychology: Human Perception \& Performance, 28, 431-446.

Gorno-Tempini, M. L., \& Price, C. J. (2001). Identification of famous faces and buildings: A functional neuroimaging study of semantically unique items. Brain, 124, 2087-2097.

Grill-Spector, K., Knouf, N., \& Kanwisher, N. (2004). The fusiform face area subserves face perception, not generic within-category identification. Nature Neuroscience, 7, 555-562.

Hole, G. J. (1994). Configurational factors in the perception of unfamiliar faces. Perception, 23, 65-74.

Holmes, A., Vuilleumier, P., \& Eimer, M. (2003). The processing of emotional facial expression is gated by spatial attention: Evidence from event-related brain potentials. Cognitive Brain Research, 16, 174-184.

JACKSON, M. C., \& RAYMOND, J. E. (2004). Visual working memory for faces [Abstract]. Journal of Vision, 4, 394a.

JEFFREYS, D. A. (1996). Evoked potential studies of face and object processing. Visual Cognition, 3, 1-38.

Jenkins, R., LAVIE, N., \& Driver, J. (2003). Ignoring famous faces: Category-specific dilution of distractor interference. Perception \& Psychophysics, 65, 298-309.

JOLICGEUR, P. (1999). Restricted attentional capacity between sensory modalities. Psychonomic Bulletin \& Review, 6, 87-92.

KANWISHER, N. (2000). Domain specificity in face perception. Nature Neuroscience, 3, 759-763.

Kanwisher, N., McDermott, J., \& Chun, M. M. (1997). The fusiform face area: A module in human extrastriate cortex specialized for face perception. Journal of Neuroscience, 17, 4302-4311.

Kanwisher, N., \& Potter, M. (1990). Repetition blindness: Levels of processing. Journal of Experimental Psychology: Human Perception \& Performance, 16, 30-47.

Kuehn, S. M., \& Jolicceur, P. (1994). Impact of quality of the image, orientation, and similarity of the stimuli on visual search for faces. Perception, 23, 95-122.

Lavie, N., Ro, T., \& Russell, C. (2003). The role of perceptual load in processing distractor faces. Psychological Science, 14, 510-515.

Leveroni, C. L., Seidenberg, M., Mayer, A. R., Mead, L. A., Binder, J. R., \& RAO, S. M. (2000). Neural systems underlying the recognition of familiar and newly learned faces. Journal of Neuroscience, 20, 878-886.

LiU, J., Harris, A., \& Kanwisher, N. (2002). Stages of processing in face perception: An MEG study. Nature Neuroscience, 5, 910-916.

Liu, J., Higuchi, M., Marantz, A., \& Kanwisher, N. (2000). The selectivity of the occipitotemporal M170 for faces. NeuroReport, 11, 337-341.

LuCK, S. J., \& BEACH, N. J. (1998). Visual attention and the binding problem: A neurophysiological perspective. In R. Wright (Ed.), Visual attention (pp. 455-478). Oxford: Oxford University Press. 
MACK, A., \& Rock, I. (1998). Inattentional blindness. Cambridge, MA: MIT Press.

McCarthy, G., Puce, A., Gore, J. C., \& Allison, T. (1997). Facespecific processing in the human fusiform gyrus. Journal of Cognitive Neuroscience, 9, 604-609.

Moscovitch, M., \& Moscovitch, D. A. (2000). Super face-inversion effects for isolated internal or external features, and for fractured faces. Cognitive Neuropsychology, 17, 201-219.

Moscovitch, M., Winocur, G., \& Behrmann, M. (1997). What is special about face recognition? Nineteen experiments on a person with visual object agnosia and dyslexia but normal face recognition. Journal of Cognitive Neuroscience, 9, 555-604.

Nothdurft, H. C. (1993). Faces and facial expressions do not pop out. Perception, 22, 1287-1298.

Palermo, R., \& Rhodes, G. (2002). The influence of divided attention on holistic face perception. Cognition, 82, 225-257.

Pashler, H. E. (1998). The psychology of attention. Cambridge, MA: MIT Press.

Pessoa, L., Kastner, S., \& Ungerleider, L. G. (2002). Attentional control of the processing of neutral and emotional stimuli. Cognitive Brain Research, 15, 31-45.

Pessoa, L., McKenna, M., Gutierrez, E., \& Ungerleider, L. G. (2002). Neural processing of emotional faces requires attention. Proceedings of the National Academy of Sciences, 99, 11458-11463.

RAYMOND, J. E. (2003). New objects, not new features, trigger the attentional blink. Psychological Science, 14, 54-59.

Raymond, J. E., Shapiro, K. L., \& Arnell, K. M. (1992). Temporary suppression of visual processing in an RSVP task: An attentional blink? Journal of Experimental Psychology: Human Perception \& Performance, 18, 849-860.

Raymond, J. E., Shapiro, K. L., \& Arnell, K. M. (1995). Similarity determines the attentional blink. Journal of Experimental Psychology: Human Perception \& Performance, 21, 653-662.

Reed, C. L., Stone, V. E., Bozova, S., \& Tanaka, J. (2003). The bodyinversion effect. Psychological Science, 14, 302-308.

Rhodes, G., Brake, S., \& Atkinson, A. P. (1993). What's lost in inverted faces? Cognition, 47, 25-57.

Rossion, B., Gauthier, I., Goffaux, V., Tarr, M. J., \& CrommeLINCK, M. (2002). Expertise training with novel objects leads to leftlateralized facelike electrophysiological responses. Psychological Science, 13, 250-257.

Schneider, W., Eschman, A., \& Zuccolotto, A. (2002). E-Prime user's guide. Pittsburgh: Psychology Software Tools.

SCHNEIDER, W., \& ShIFFrin, R. M. (1977). Controlled and automatic human information processing: I. Detection, search, and attention. Psychological Review, 84, 1-66.

Shah, N. J., Marshall, J. C., Zafiris, O., Schwab, A., Zilles, K., MARKowitsch, H. J., \& FinK, G. R. (2001). The neural correlates of person familiarity: A functional magnetic resonance imaging study with clinical implications. Brain, 124, 804-815.

Shapiro, K. L., Arnell, K. M., \& RaYmond, J. E. (1997). The attentional blink. Trends in Cognitive Sciences, 1, 291-296.

Shapiro, K. L., Caldwell, J., \& Sorensen, R. E. (1997). Personal names and the attentional blink: A visual "cocktail party" effect. Journal of Experimental Psychology: Human Perception \& Performance, 23, 504-514.

Shapiro, K. L., Raymond, J. E., \& Arnell, K. M. (1994). Attention to visual pattern information produces the attentional blink in rapid serial visual presentation. Journal of Experimental Psychology: Human Perception \& Performance, 20, 357-371.
Shen, J., \& ReINGOLD, E. M. (2001). Visual search asymmetry: The influence of stimulus familiarity and low-level features. Perception \& Psychophysics, 63, 464-475.

SHIFFrin, R. M., \& SchneIDER, W. (1977). Controlled and automatic human information processing: II. Perceptual learning, automatic attending, and a general theory. Psychological Review, 84, 127-190.

Sinha, P., \& PogGio, T. (1996). Role of learning in three-dimensional form perception. Nature, 384, 460-463.

Soto-Faraco, S., Spence, C., Fairbank, K., Kingstone, A., HillSTROM, A. P., \& ShapIRo, K. [L.] (2002). A crossmodal attentional blink between vision and touch. Psychonomic Bulletin \& Review, 9, 731-738.

TanaKa, J. W., \& Farah, M. J. (1993). Parts and wholes in face recognition. Quarterly Journal of Experimental Psychology, 46A, 225-245.

TANAKa, J. W., \& SEngCo, J. A. (1997). Features and their configuration in face recognition. Memory \& Cognition, 25, 583-592.

TipPeR, S. P., \& Cranston, M. (1985). Selective attention and priming: Inhibitory and facilitatory effects of ignored primes. Quarterly Journal of Experimental Psychology, 73A, 591-611.

Tong, F., \& NAKAYAMA, K. (1999). Robust representations for faces: Evidence from visual search. Journal of Experimental Psychology: Human Perception \& Performance, 25, 1016-1035.

Treisman, A. (1996). The binding problem. Current Opinion in Neurobiology, 6, 171-178.

Visser, T. A. W., Bischof, W. F., \& Di Lollo, V. (1999). Attentional switching in spatial and nonspatial domains: Evidence from the attentional blink. Psychological Bulletin, 125, 458-469.

Vuilleumier, P., Armony, J. L., Driver, J., \& Dolan, R. J. (2001). Effects of attention and emotion on face processing in the human brain: An event-related fMRI study. Neuron, 30, 1-20.

Whalen, P. J., Rauch, S. L., Etcoff, N. L., Mcinerney, S. C., Lee, M. B., \& JENIKE, M. A. (1998). Masked presentations of emotional facial expressions modulate amygdala activity without explicit knowledge. Journal of Neuroscience, 18, 411-418.

WoJCIUlik, E., KANWISHer, N., \& Driver, J. (1998). Covert visual attention modulates face-specific activity in the human fusiform gyrus: fMRI study. Journal of Neurophysiology, 79, 1574-1578.

Young, A. W., Ellis, A. W., Flude, B. M., McWeeny, K. H., \& Hay, D. C. (1986). Face-name interference. Journal of Experimental Psychology: Human Perception \& Performance, 12, 466-475.

Young, A. W., Hellawell, D., \& Hay, D. C. (1987). Configurational information in face perception. Perception, 16, 747-759.

\section{NOTES}

1. Across all our experiments, we found no systematic effect of T1 type (circles vs. squares) on T2 performance, precluding the argument that the $\mathrm{T} 1$ circles image might have been more face-like than the squares image and contributed especially to our $\mathrm{AB}$ finding.

2 . When lag 1 data was excluded from all other conditions, a repeated measures ANOVA with lag $(2,3,4,5$, and baseline) as a withinparticipants factor did not alter the results reported when lag 1 was included. That is, with lag 1 excluded, the main effect of lag remained statistically significant in Groups U-U and U-F and in Experiment 2 (Group OE) and was nonsignificant in Group $\mathrm{F}-\mathrm{U}$.

(Manuscript received October 6, 2004; revision accepted for publication June 20,2005.) 